\title{
Rare Gastric Lesions Associated with Helicobacter pylori Infection: A Histopathological Review
}

\author{
Mee Joo \\ Department of Pathology, Inje University Ilsan \\ Paik Hospital, Goyang, Korea \\ Received: November 10, 2016 \\ Accepted: April 3, 2017 \\ Corresponding Author \\ Mee Joo, MD, PhD \\ Department of Pathology, Inje University \\ Ilsan Paik Hospital, 170 Juhwa-ro, Ilsanseo-gu, \\ Goyang 10380, Korea \\ Tel: $+82-31-910-7141$ \\ Fax: +82-31-910-7139 \\ E-mail: mjoo@paik.ac.kr
}

\begin{abstract}
Helicobacter pylori infection is associated with chronic gastritis, peptic ulcer disease, gastric adenocarcinoma, and mucosa-associated lymphoid tissue lymphoma. However, some rare gastric lesions exhibiting distinctive histological features may also be associated with $\mathrm{H}$. pylori infection, including lymphocytic gastritis, granulomatous gastritis, Russell body gastritis, or crystal-storing histiocytosis. Although diverse factors can contribute to their development, there is convincing evidence that $H$. pylori infection may play a pathogenic role. These findings are mainly based on studies in patients with these lesions who exhibited clinical and histological improvements after $H$. pylori eradication therapy. Thus, $H$. pylori eradication therapy might be indicated in patients with no other underlying disease, particularly in countries with a high prevalence of $H$. pylori infection. This review describes the characteristic histological features of these rare lesions and evaluates the evidence regarding a causative role for $\mathrm{H}$. pylori infection in their pathogenesis.
\end{abstract}

Key Words: Helicobacter pylori; Stomach; Gastritis; Rare; Immunoglobulins
Helicobacter pylori is a common gastric pathogen that causes gastritis, peptic ulcer disease, gastric adenocarcinoma, and mucosa-associated lymphoid tissue (MALT) lymphoma. H. pylori infection has been linked to a number of rare gastric mucosal lesions with distinctive histological features, including rare forms of gastritis, such as lymphocytic gastritis $(\mathrm{LG})^{1-5}$ or granulomatous gastritis (GG), ${ }^{3,4,6,7}$ and abnormal immunoglobulin deposits, such as Russell body gastritis (RBG) $)^{8,9}$ or crystal-storing histiocytosis $(\mathrm{CSH}){ }^{10,11}$ These lesions are easily diagnosed based on their distinctive histological features; however, their development can be attributed to various factors besides $H$. pylori infection. Therefore, the role of $H$. pylori as a causative organism remains debatable, and it has been suggested that $H$. pylori may be an "innocent bystander.",,4,12 Nevertheless, $H$. pylori eradication therapy has been linked to clinical and histological improvements in a subset of these lesions, ${ }^{7,23-21}$ which supports the role of $H$. pylori infection in their development and implies that $H$. pylori eradication therapy could be an effective treatment. Therefore, in this review, we investigate the relationship between these rare gastric lesions and $H$. pylori infection, describe their characteristic histological features, and evaluate the role of $H$. pylori infection in their pathogenesis.

\section{RARE FORMS OF GASTRITIS}

LG and GG are not distinct clinicopathological entities, but rather morphologic patterns of injury that can be secondary to a variety of underlying etiologies. ${ }^{2-4,6}$ The histological identification of intraepithelial lymphocytosis and granuloma formation are key diagnostic features of LG and GG, respectively. ${ }^{1-7}$ However, a morphological diagnosis of LG and GG should elicit clinical and laboratory workups to identify the underlying etiology. In Western countries, LG and GG are generally classified as special forms of $H$. pylori-negative gastritis. ${ }^{3,4}$ However, there is convincing evidence that $H$. pylori infection contributes to the pathogenesis of both $\mathrm{LG}^{1,5}$ and GG, ${ }^{6,7,22}$ and that $H$. pylori eradication therapy may be an effective treatment. ${ }^{7,13-15,17,23,24}$ Thus, it is possible that subsets of LG and GG could be categorized as $H$. pylori-associated gastritis. The potential role of $H$. pylori infection in the pathogenesis of each of these lesions is described below, along with their histopathological characteristics.

\section{Lymphocytic gastritis}

LG, first described by Haot et al. ${ }^{25}$ in 1988 , is a rare form of chronic gastritis that is characterized by a dense lymphocytic infiltration of the surface and pit gastric epithelium known as "intraepithelial lymphocytosis." LG was initially considered to be 
related to varioliform gastritis, which manifests as thickened mucosa with "octopus-sucker" targetoid erosions; ${ }^{25,26}$ however, the endoscopic features of LG vary according to its severity, ranging from normal to hypertrophic. ${ }^{2,27}$ Histologically, LG is defined by the presence of $\geq 25$ intraepithelial lymphocytes (IELs) per 100 epithelial cells (Fig. 1). Gastric intraepithelial lymphocytosis is associated with a variety of conditions, including celiac disease, H. pylori infection, Crohn disease, syphilis, hypertrophic gastropathy, Ménétrier's disease, human immunodeficiency virus, and lymphoma. ${ }^{2,5}$ However, celiac disease and $H$. pylori infection are the main causes of LG, accounting for $38 \%$ and $29 \%$ of cases, respectively. ${ }^{5,13,28}$ The association between LG and celiac disease is relatively well established. Mild intraepithelial lymphocytosis with a low cut-off value ( $\geq 8$ IELs/100 epithelial cells) has been observed in $84 \%$ of patients with celiac disease, ${ }^{29}$ and LG occurs in up to $45 \%$ of patients, with resolution of $L G$ in response to a gluten-free diet. ${ }^{5,13,28-30}$

However, questions remain regarding the role of $H$. pylori infection in the development of LG due to the discrepancy between the prevalence of $H$. pylori in the general population and the inci- dence of LG among patients with $H$. pylori-associated gastritis. ${ }^{2-4}$ Given the high global prevalence of $H$. pylori infection, it is unclear why the proportion of $H$. pylori-infected patients presenting with LG morphology $(<5 \%)$ is so low. ${ }^{5}$ Nevertheless, $H$. pylori eradication therapy can resolve $H$. pylori-associated LG by reducing IEL levels, and has been shown to improve symptoms and/or lead to regression of the gastritis, ${ }^{13-16}$ which supports a causal role of $H$. pylori infection in the development of LG. Previous studies have reported that $H$. pylori-associated LG frequently exhibits significant neutrophilic activity in addition to intraepithelial lymphocytosis, ${ }^{2,3,16,27}$ which is distinct from celiac diseaseassociated LG that exhibits intraepithelial lymphocytosis without neutrophilic infiltration. In this context, Nielsen $e t$ al. ${ }^{27}$ argued that $H$. pylori-associated intraepithelial lymphocytosis accompanied with significant neutrophilic infiltration should be considered "chronic active gastritis," rather than LG. However, considering the fact that LG is a morphological diagnosis that is based on the presence of intraepithelial lymphocytosis ( $\geq 25$ IELs per 100 epithelial cells), the use of the term "LG" remains relevant.

Interestingly, a considerable number of patients with LG and
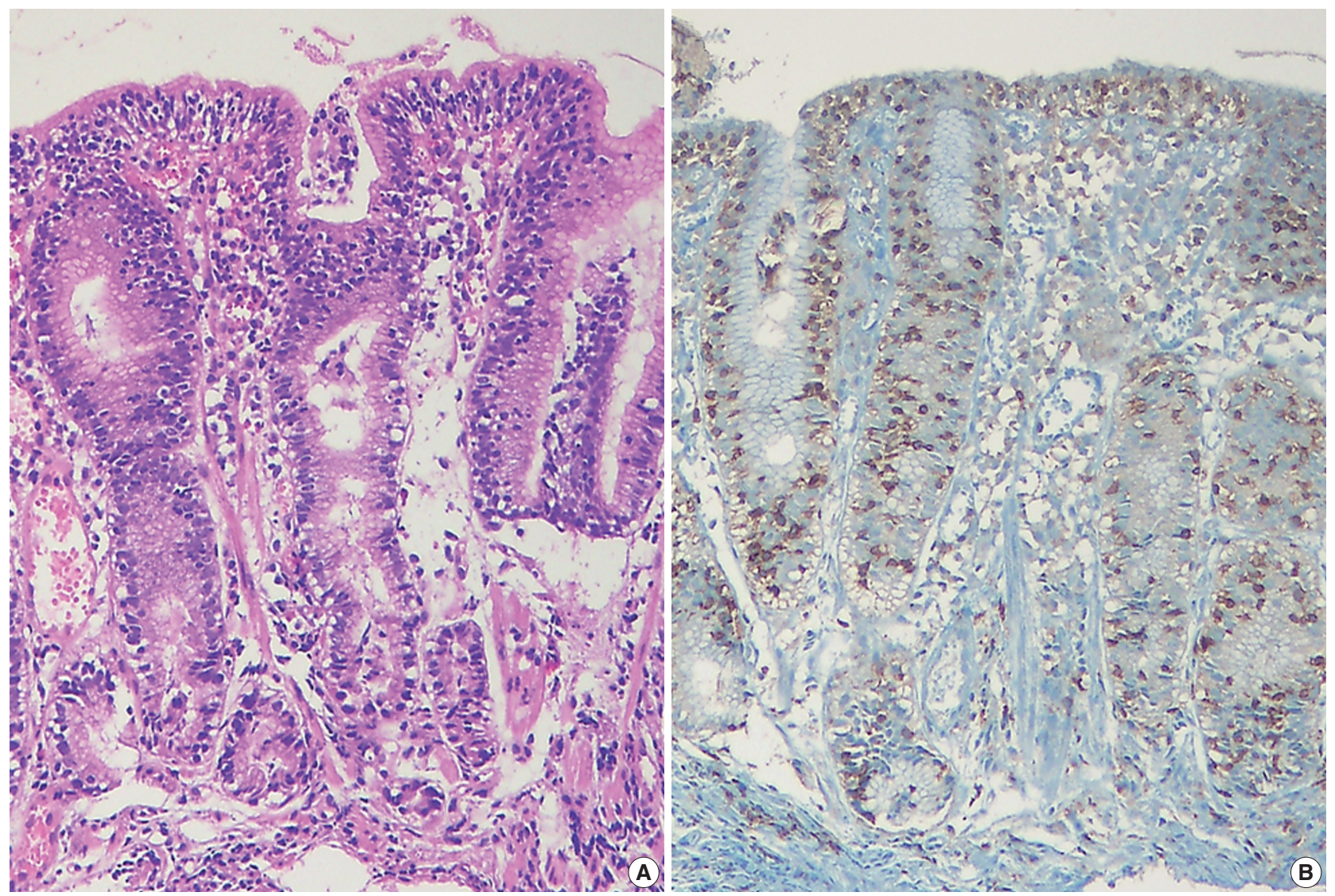

Fig. 1. Lymphocytic gastritis. (A) The biopsy specimen shows a marked increase in intraepithelial lymphocytes (IELs) (over 25 IELs per 100 epithelial cells) with a top-heavy distribution. (B) Most IELs are positive for CD3 immunostaining. 
positive $H$. pylori serology did not exhibit histological evidence of $H$. pylori infection. ${ }^{1,14,15,27}$ In addition, the beneficial effects of $H$. pylori eradication therapy in LG have been observed in patients who had positive serology but negative histology for $H$. $p y$ lori. ${ }^{14,15}$ Furthermore, even when $H$. pylori infection has been histologically confirmed in patients with LG, colonization tends to be mild and focal. ${ }^{14,15}$ These results imply that failure to histologically detect $H$. pylori may be related to sampling error due to low-level infection. ${ }^{27}$ Also, it is possible that LG development is a local, transient, or delayed immunological reaction to $H$. pylo$r i$ infection, and is not a direct effect of the infection. ${ }^{1,13,14,27}$ Thus, if other causes can be excluded, $H$. pylori eradication therapy could be considered in symptomatic patients with LG who are histologically and/or serologically positive for $H$. pylori. This approach may be more appropriate in countries with a low prevalence of celiac disease and a high prevalence of $H$. pylori infection, even without histological detection of $H$. pylori.

IELs are functionally and phenotypically distinct from peripheral lymphocytes, and the majority of IELs in the gastrointestinal epithelium are $\mathrm{CD}^{+} / \mathrm{CD}^{+} \mathrm{T}$ cells with cytotoxic potential. ${ }^{31}$ These IELs are thought to play an important role in mucosal immunity and have also been implicated in epithelial cell turnover by eliciting apoptosis through cytotoxic T-lymphocytes (CTLs). ${ }^{31,32}$ Recently, Han et al. ${ }^{33}$ studied IEL subpopulations and their cytotoxicity in $\mathrm{H}$. pylori-infected gastric mucosa using T-cell-restricted intracellular antigen-1 (TIA-1; a marker for resting and activated CTLs) and granzyme B (GrB; a marker for activated CTLs). They found that the IELs consisted of a mixture of TIA $-1^{+} / \mathrm{GrB}^{-}$CTLs, TIA $-1^{+} / \mathrm{GrB}^{+}$CTLs, and $\mathrm{CD}^{+}{ }^{+} \mathrm{T}$ cells in the infected mucosa. In addition, they found that $H$. pylori-associated LG was distinct from $H$. pylori gastritis, based on the increased IEL levels and changes in the cytotoxicity and distribution of the subpopulations: $H$. pylori-associated LG had a higher proportion of activated $\mathrm{GrB}^{+}$CTLs, compared to $H$. pylori gastritis. There was also a parallel increase in epithelial apoptosis. Meanwhile, in a study by Oberhuber et al. ${ }^{34}$ the proportion of $\mathrm{GrB}^{+}$CTLs in $H$. pylori-associated LG (10.8\%) was lower than that in idiopathic LG (12\%) or celiac disease-associated LG (18.9\%). Thus, although LG exhibits consistent histological features (regardless of etiology), IEL characteristics may vary depending on the underlying condition, which can lead to different clinical manifestations.

\section{Granulomatous gastritis}

GG is a rare disease that is characterized by the presence of granulomas, and is detected in $0.01 \%-0.35 \%$ of gastric biop- sies. ${ }^{6,717,35} \mathrm{GG}$ can be caused by a number of factors, including systemic disease (e.g., Crohn disease, sarcoidosis, or vasculitis), infection (e.g., tuberculosis, histoplasmosis, or syphilis), underlying malignancy, or foreign bodies. ${ }^{4,6,736}$ Crohn's disease and gastric sarcoidosis are the two leading causes of GG, accounting for 20\%-50\% of cases in Western countries. ${ }^{6,35}$ Isolated or idiopathic granulomatous gastritis (IGG) was first described by Fahimi et al..$^{37}$ in 1965 , and is diagnosed by the exclusion of other granulomatous diseases. However, whether IGG can be considered a discrete condition remains controversial, as it is possible that a clear etiology could be identified through a more meticulous clinical work-up and long-term follow-up.

Dhillon and Sawyerr ${ }^{22}$ first reported an association between GG and $H$. pylori infection in 1989. Since then a number of reports have been published that support their findings. $6.7,17,18,23,24,38-42$ These reports demonstrated that the mucosa surrounding granulomas in GG exhibits typical histological features of $H$. pylori gastritis, that features suggestive of other etiologies are absent, and that $H$. pylori eradication therapy can result in GG resolution. However, whether $H$. pylori plays a causative role in the pathogenesis of GG remains debatable. First, the incidence of GG is abnormally low relative to the $H$. pylori prevalence in the general population. ${ }^{6,712,35}$ Although Ectors et al. ${ }^{6}$ and Maeng et al. ${ }^{7}$ have reported the presence of $H$. pylori in $92 \%$ and $89 \%$ of GG cases, respectively, the overall incidences of GG were only $0.27 \%$ and $0.08 \%$, respectively. Second, $H$. pylori organisms are rarely found within granulomas, implying $H$. pylori infection is a comorbidity rather than a cause in GG pathogenesis. Lastly, in cases of GG with $H$. pylori infection, granulomas often persist for 3-17 months after $H$. pylori eradication therapy, ${ }^{17,24,39}$ making its efficacy in GG questionable. It is plausible that although $H$. pylori can cause GG, granuloma formation is the result of a rare host response as opposed to a direct effect. Thus, $H$. pylori eradication therapy would be less effective in the resolution of GG, compared to its efficacy in conventional $H$. pylori gastritis.

Histologically, H. pylori-associated GG exhibits small nonnecrotizing epithelioid granulomas with Langhans giant cells (Fig. 2), which are similar to those that are associated with sarcoidosis or Crohn disease. These granulomas tend to form in distinctive locations, such as the foveolar isthmi, ${ }^{6}$ with Maeng et al. ${ }^{7}$ reporting that the majority $(66.7 \%)$ of granulomas were found there. They are also often in contact with a damaged pit (where $H$. pylori are commonly found) and are frequently accompanied by prominent neutrophilic infiltration, which distinguishes them from the granulomas that are observed in Crohn disease or sarcoidosis. ${ }^{6,7}$ However, this characteristic morphology and local- 

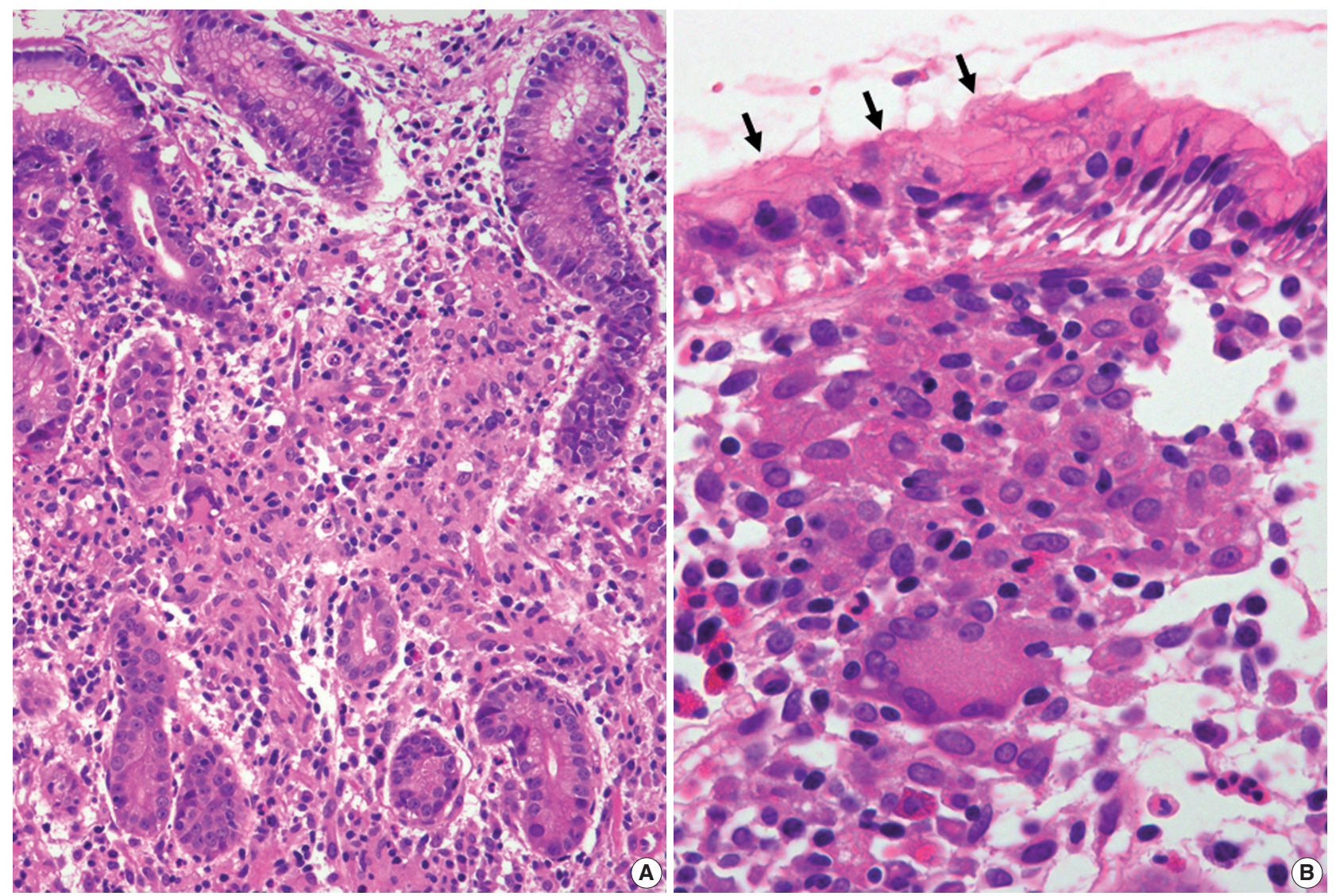

Fig. 2. Granulomatous gastritis. (A) The biopsy specimen demonstrates diffuse chronic active gastritis with confluent granulomas including multinucleated giant cells. (B) A well-defined granuloma is noted just below the surface foveolar epithelium. Some Helicobacter pylori organisms are seen (arrows).

ization has not been consistently reported in subsequent studies. $18,23,24,40-42$ Therefore, there are no distinct histologic features that could be used to confirm H. pylori-associated GG. Rather, it appears that the conditions in the mucosa surrounding granulomas are more informative, ${ }^{3,4,7}$ as the presence of $H$. pylori and neutrophil-rich chronic active gastritis (associated with glandular atrophy or intestinal metaplasia) increase the likelihood of $H$. pylori infection. Taken together, although the presence of $H$. pylori in the vicinity of granulomas does not imply a causative association, $H$. pylori eradication therapy should be considered when there are no other underlying disease except $H$. pylori infection.

\section{INTRACELLULAR IMMUNOGLOBULIN ACCUMULATION IN ASSOCIATION WITH HELICOBACTER PYLORI INFECTION}

Immunoglobulin accumulations can be found in reactive and neoplastic plasma cells and include large intracytoplasmic spheri- cal inclusions (Russell bodies), small intracytoplasmic morular inclusions (Mott cells), intranuclear inclusions (Dutcher bodies), and rare angular- or needle-shaped intracytoplasmic crystalline inclusions. These accumulations are associated with chronic inflammation with plasmacytosis, autoimmune disease, multiple myeloma, or other B-cell lymphomas. ${ }^{43-45}$ Although the exact mechanism of immunoglobulin accumulation is unclear, it may be due to simple over-production, altered production, abnormal secretion, or impaired excretion. ${ }^{46,47}$ In the gastric mucosa, diffuse plasma cell infiltration with immunoglobulin overproduction may result from chronic over-stimulation of plasma cells by mucosal pathogens, especially $H$. pylori. Scattered Russell bodies are often observed with $H$. pylori gastritis, whereas Dutcher bodies are frequently associated with low-grade MALT lymphoma. However, RBG and CSH are rarely reported in the stomach. ${ }^{9,10}$ As the incidence of these lesions is low relative to $H$. pylori-associated gastritis, the contribution of $H$. pylori infection to their development is questionable. Furthermore, careful evaluation of their underlying cause is essential, as they can be associated with 
monoclonal gammopathy or lymphoreticular neoplasms. ${ }^{20,43,48}$ The possible connections between $H$. pylori infection and these immunoglobulin accumulations, diagnostically relevant histological features, and biological significance are described below.

\section{Russell body gastritis}

The first case of RBG was reported by Tazawa and Tsutsumi in 1998. ${ }^{19} \mathrm{RBG}$ is a rare form of chronic gastritis characterized by localized accumulation of Mott cells, which are plasma cells with a cytoplasm packed with small spherical inclusions (Fig. 3A, B). These lesions are rare, and only 30 cases of RBG have been published to date in the English literature. ., $919-21,48-61^{2}$ The clinical and pathological features of RBG are summarized in Table 1. Although its pathogenesis has not been fully elucidated, there is evidence to support a strong association between $H$. pylori infection and RBG development. For example, H. pylori is detected in approximately two-thirds of patients with RBG. ${ }^{8,9,19-21,48,50,52,53,55,57,60,61}$ Few other infections that have been reported with RBG include human immunodeficiency virus (three patients), ${ }^{51,53,59}$ hepatitis $\mathrm{C}$ virus (one patient) ${ }^{58}$ and candida esophagitis (one case). ${ }^{49}$ In addition, more than $60 \%$ of patients with RBG exhibit lesion regression following $H$. pylori eradication therapy. ${ }^{19-21,53,60}$ Furthermore, it has been reported that highly virulent $H$. pylori genotypes (vacA and cagA) are associated with the formation of Russell bodies and Mott cells in the antral mucosa. ${ }^{62}$

Immunoglobulin light chain restriction is generally considered to be proof of monoclonality and is an important indicator of Bcell neoplasia. Interestingly, light chain restriction was detected via immunohistochemistry in 12 out of 30 cases of RBG (kappa restriction in 11 cases and lambda restriction in one case). ${ }^{9,20,48,58,61}$
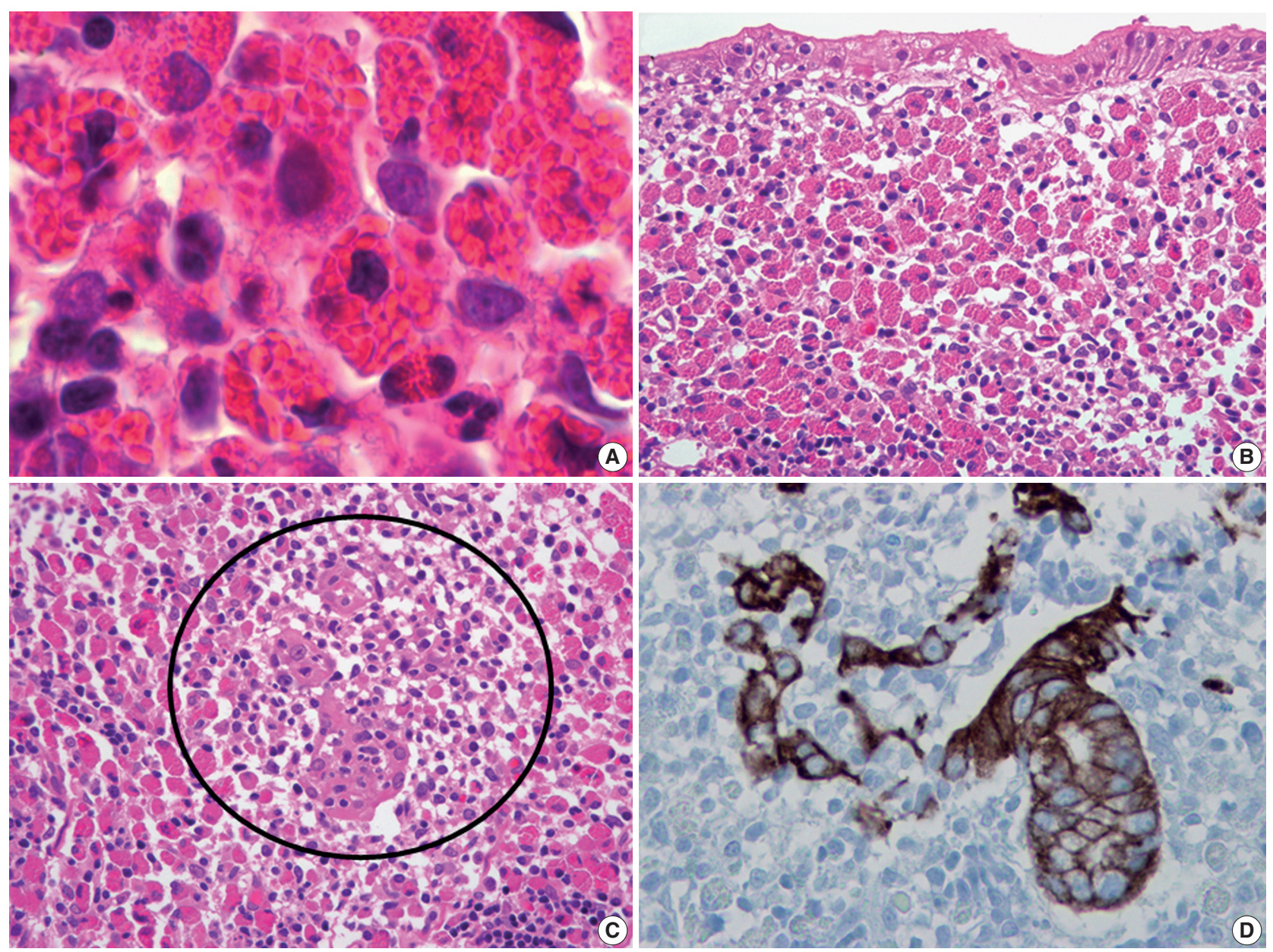

Fig. 3. Russell body gastritis with concomitant mucosa-associated lymphoid tissue lymphoma. (A) Mott cells are plasma cells in which the cytoplasm is packed with multiple variable-sized Russell bodies. (B) The lamina propria of the gastric mucosa is expanded by extensive infiltration of Mott cells, consistent with Russell body gastritis. (C) Small- to intermediate-sized atypical lymphoid cells, morphologically consistent with centrocyte-like cells are admixed with Mott cells and destroy adjacent gastric glands to form a lymphoepithelial lesion (circle). (D) Immunostaining for cytokeratin highlights a lymphoepithelial lesion. 
Table 1. Clinical and pathologic findings of previously published cases of Russell body gastritis in the English literature

\begin{tabular}{|c|c|c|c|c|c|c|c|c|}
\hline Case & Study & $\begin{array}{l}\text { Age (yr)/ } \\
\text { Sex }\end{array}$ & Endoscopic finding & $\begin{array}{c}\text { Helicobacter } \\
\text { pylori } \\
\text { infection }\end{array}$ & $\begin{array}{l}\text { Ig light chain } \\
\text { of Mott cells }\end{array}$ & Gastric lesion coexisted & $\begin{array}{l}\text { HPET/ } \\
\text { Resolution } \\
\text { of RBG }\end{array}$ & Others \\
\hline 1 & Tazawa and Tsutsumi' ${ }^{19}$ & $53 / \mathrm{M}$ & Multiple ulcer scars & Yes & Polyclonal & None & Done/Yes & - \\
\hline 2 & Erbersdobler et al. ${ }^{49}$ & $80 / F$ & Irregular mucosal swelling & No & Polyclonal & None & NS & $\begin{array}{l}\text { Candida } \\
\text { esophagitis }\end{array}$ \\
\hline 3 & Ensari et al..$^{50}$ & 70/M & Flattened gastric folds & Yes & Polyclonal & None & Done/NS & - \\
\hline 4 & Paik et al..$^{8}$ & $47 / F$ & Erythematous swelling & Yes & Polyclonal & None & Done/NS & - \\
\hline 5 & Paik et al..$^{8}$ & $53 / F$ & Yellowish raised lesion & Yes & Polyclonal & None & Done/NS & - \\
\hline 6 & Wolkersdörfer et al. ${ }^{20}$ & $54 / \mathrm{M}$ & Erythema and erosions & Yes & Monoclonal $(\lambda)$ & None & Done/Yes & MGUS \\
\hline 7 & Drut and Olenchuk ${ }^{51}$ & $34 / \mathrm{M}$ & Elevation with central macule & No & Polyclonal & None & NS & HIV infection \\
\hline 8 & Pizzolitto et al. ${ }^{52}$ & $60 / F$ & Minute-raised granular areas & Yes & Polyclonal & None & Done/NS & - \\
\hline 9 & Licci et al..$^{53}$ & $59 / \mathrm{M}$ & Hyperemia & Yes & Polyclonal & None & Done/Yes & HIV infection \\
\hline 10 & Habib et al..$^{54}$ & $75 / \mathrm{M}$ & $\begin{array}{l}\text { Nodular chronic active } \\
\text { gastritis }\end{array}$ & No & Polyclonal & None & NS & - \\
\hline 11 & Shinozaki et al..$^{55}$ & $74 / \mathrm{M}$ & $\begin{array}{l}\text { Centrally ulcerated bulky } \\
\text { mass }\end{array}$ & Yes & Polyclonal & EBV-positive carcinoma & No & - \\
\hline 12 & Shinozaki et al..$^{55}$ & $29 / F$ & Ulcerated mass & Yes & Polyclonal & EBV-positive carcinoma & No & - \\
\hline 13 & Del Gobbo et al..$^{56}$ & $78 / F$ & Hyperemic gastric mucosa & No & Polyclonal & None & No & - \\
\hline 14 & Wolf et al. ${ }^{57}$ & $67 / M$ & Exophytic tumor & Yes & NS & Signet ring cell carcinoma & No & - \\
\hline 15 & Coryne and Azadeh ${ }^{58}$ & $49 / M$ & Severe raised erosive gastritis & No & Monoclonal (к) & None & NS & HCV infection \\
\hline 16 & Bhalla et al..$^{59}$ & $82 / \mathrm{M}$ & Gastritis & No & Polyclonal & None & NS & HIV infection \\
\hline 17 & Karabagli and Gokturk ${ }^{60}$ & $60 / M$ & Large ulcerofungating mass & Yes & Polyclonal & None & Done/Yes & - \\
\hline 18 & Yoon et al..21 & $57 / M$ & $\begin{array}{l}\text { Elevation with central } \\
\text { depression }\end{array}$ & Yes & Polyclonal & None & Done/Yes & - \\
\hline 19 & Yoon et al..$^{21}$ & $43 / \mathrm{M}$ & $\begin{array}{l}\text { Whitish flat lesion with } \\
\text { nodularity }\end{array}$ & Yes & Polyclonal & None & Done/Yes & - \\
\hline 20 & Araki et al. ${ }^{61}$ & $74 / F$ & Ulcer & Yes & Monoclonal (к) & None & No & - \\
\hline 21 & Zhang et al. ${ }^{9}$ & $78 / F$ & Gastritis with uneven mucosa & No & Monoclonal ( $\kappa)$ & None & No & - \\
\hline 22 & Zhang et al. ${ }^{9}$ & $77 / F$ & Gastritis with uneven mucosa & Yes & Monoclonal (k) & None & No & - \\
\hline 23 & Zhang et $a l^{9}$ & $77 / F$ & Punctiform erosion & Yes & Monoclonal ( $\mathrm{k}$ ) & None & No & - \\
\hline 24 & Zhang et al. ${ }^{9}$ & $56 / \mathrm{M}$ & Raised erosion & Yes & Monoclonal ( $\mathrm{\kappa}$ ) & None & No & - \\
\hline 25 & Zhang et $a l^{9}$ & $76 / \mathrm{M}$ & Erythema & Yes & Monoclonal ( $\mathrm{\kappa}$ ) & None & No & - \\
\hline 26 & Zhang et al. ${ }^{9}$ & $50 / \mathrm{M}$ & Flat and raised erosions & Yes & Monoclonal (к) & None & No & - \\
\hline 27 & Zhang et al. ${ }^{9}$ & $28 / \mathrm{M}$ & Erythema & No & Monoclonal (к) & None & No & - \\
\hline 28 & Zhang et al. ${ }^{9}$ & $24 / F$ & Erythema & No & Monoclonal (k) & None & No & - \\
\hline 29 & Zhang et al. ${ }^{9}$ & $66 / \mathrm{M}$ & Ulceration & No & NA & None & No & - \\
\hline 30 & $\mathrm{~J} \mathrm{O}^{48}$ & $56 / \mathrm{M}$ & $\begin{array}{l}\text { Hyperemia and } \\
\text { micronodularity }\end{array}$ & Yes & Monoclonal (k) & MALT Iymphoma & No & - \\
\hline
\end{tabular}

HPET, Helicobacter pylori eradication therapy; RBG, Russell body gastritis; M, male; F, female; NS, not stated; MGUS, monoclonal gammopathy of undetermined significance; HIV, human immunodeficiency virus; EBV, Epstein-Barr virus; HCV, hepatitis C virus; NA, not assessed; MALT, mucosa-associated lymphoid tissue.

Ten of these cases were localized gastric lesions with no associated lymphoid malignancy or plasma cell disorder, although one case was associated with low-grade MALT lymphoma, ${ }^{48}$ and another with concomitant monoclonal gammopathy of undetermined significance. ${ }^{20}$ This could be explained by the findings of Girón and Shah, ${ }^{63}$ who reported that approximately $50 \%$ of patients with $H$. pylori infection exhibit either kappa or lambda light chain elevation, and suggested that $H$. pylori infection might contribute to immunoglobulin light chain dysfunction. Thus, RBG may be closely associated with $H$. pylori infection, and the majority of RBG cases may be reactive in nature, even when light chain monoclonality is detected. Nevertheless, pathologists should be aware of the possibility of concomitant lymphoid neoplasms.

Given the strong association with $H$. pylori infection, it is possible that RBG, gastric carcinoma, or MALT lymphoma might occur simultaneously in the same patient. Previous reports describe Mott cell proliferation (features of RBG) in association with gastric carcinoma, including two cases of Epstein-Barr virus-positive lymphoepithelioma-like carcinoma, ${ }^{55}$ and one case of signet ring cell carcinoma. ${ }^{57}$ In these cases, Mott cell proliferation was likely a reactive paraneoplastic event, given that the carcinoma and Mott cells did not mix and that the Mott cells were 
polyclonal. However, in the previously described case of RBG with concomitant MALT lymphoma ${ }^{48}$ the Mott cells were mixed with the neoplastic centrocyte-like cells (Fig. 3C) and exhibited IgM kappa monoclonality, which indicates the proliferating Mott cells were neoplastic components of MALT lymphoma.

Morphologically, Mott cells with eccentric nuclei and abundant eosinophilic cytoplasm are similar to poorly differentiated carcinoma cells or signet ring cells. In addition, in cases with abundant Mott cells and a few neoplastic cells, neoplastic cells may not be easily detected. Thus, immunostaining for cytokeratin should be conducted to exclude associated carcinoma. ${ }^{55,57}$ Furthermore, if light chain monoclonality is detected, pathologists should consider associated MALT lymphoma and perform ancillary immunostaining (e.g., for CD20 and cytokeratin) to identify centrocytelike cells and lymphoepithelial lesions (Fig. 3D). ${ }^{48}$

\section{Crystal-storing histiocytosis}

$\mathrm{CSH}$ is a rare condition, which often occurs with disorders such as monoclonal gammopathy, B-cell lymphoma, or plasma cell myeloma. ${ }^{43,64,65}$ Although many cases of $\mathrm{CSH}$ are systemic, organ-confined CSH has been described in the lung, lymph node, kidney, thyroid, thymus, parotid gland, and cornea. ${ }^{43,65-71} \mathrm{CSH}$ is extremely rare in the stomach, and only eight cases of gastric $\mathrm{CSH}$ have been described to date in the English literature (Table 2). ${ }^{10,11,43,71,72}$ Among these, $H$. pylori infection was identified in four patients (50\%) who did not exhibit concomitant gastric lesions (except for $H$. pylori gastritis) or a systemic disorder that might have caused monoclonal gammopathy. ${ }^{10,11}$ In the other four patients, there was no mention of $H$. pylori infection, ${ }^{43,71,72}$ and two of them were subsequently diagnosed with thymic lympho$\mathrm{ma}^{43}$ and plasma cell myeloma, ${ }^{71}$ respectively. Therefore, although overproduction of immunoglobulin due to $H$. pylori infection could be a plausible cause of isolated gastric $\mathrm{CSH}$, clinical workup is needed to exclude the possibility that it is a manifestation of underlying lymphoma or plasma cell myeloma. Light chain restriction was detected in five of seven cases (kappa restriction in two case and lambda restriction in three cases) ${ }^{10,71,72}$ all of which except one had no associated B-cell/plasmacytic neoplasms. Thus, light chain restriction detected in isolated gastric $\mathrm{CSH}$ does not necessarily mean that it is associated with B-cell or plasmacytic neoplasm. Meanwhile, because no studies have reported $\mathrm{CSH}$ responding to $H$. pylori eradication therapy, its effectiveness is unclear.

Histologically, CSH is characterized by diffuse infiltrations of large, oval, polygonal, and, occasionally, spindle cells, with abundant eosinophilic cytoplasm and small eccentric nuclei. The eosinophilic cytoplasm is filled with elongated, rectangular, and needleshaped/fibrillary crystalline inclusions (Fig. 4). These crystalline inclusions are approximately 5-20 nm long and are frequently arranged in parallel arrays. ${ }^{11,43,66}$ At low magnification, nodular aggregates of these cells can sometimes resemble adult rhabdomyomas or granular cell tumors in the way that they expand or displace normal structures, and proliferations of benign-looking histiocyte-like cells can also resemble Gaucher disease or malakoplakia. ${ }^{43,65,73,74}$ Therefore, immunostaining for desmin, smooth muscle actin, S100 protein, and immunoglobulin light chains can facilitate an accurate diagnosis. ${ }^{11,43,65,66,74}$

\section{CONCLUSION}

This review examined several rare gastric lesions that have distinctive histological characteristics and are associated with a variety of conditions, including $H$. pylori infection. Although $H$. pylori may be a cause in many of these conditions, the association cannot be viewed as definite, given the low incidence of these lesions relative to the high prevalence of $H$. pylori infection, regional differences in the prevalence of $H$. pylori infection, and the possibility of other causative disorders. However, it is reasonable to consider $H$. pylori once other potential etiologies have been excluded. In addition, it is not advisable to consider $H$. $p y$ lori to be an "innocent bystander," given the considerable proportion of these lesions that can be regressed or cured with $H$. pylori eradication therapy. Therefore, it is important that pathologists properly identify a lesion's cause in order to ensure ap-

Table 2. Clinical and pathologic findings of six cases of gastric crystal-storing histiocytosis

\begin{tabular}{|c|c|c|c|c|c|c|}
\hline Case No. & Study & Age $(y r) / \operatorname{Sex}$ & Endoscopic finding & Ig light chains & Crystal-ctoring cells & Helicobacter pylori infection \\
\hline 1 & Jones et al. ${ }^{43}$ & $35 / F$ & NS & Polyclonal & Histiocytes & NS \\
\hline 2 & Stewart and Spagnolo ${ }^{10}$ & $82 / \mathrm{M}$ & Gastritis & Monoclonal (IgA $\lambda)$ & Plasma cells & Positive \\
\hline 3 & Stewart and Spagnolo ${ }^{10}$ & $81 / \mathrm{M}$ & Gastritis & $\mathrm{NA}$ & Plasma cells & Positive \\
\hline 4 & Stewart and Spagnolo ${ }^{10}$ & $52 / F$ & Gastritis & Monoclonal (IgA $\lambda)$ & Plasma cells & Positive \\
\hline 5 & Joo et al. ${ }^{11}$ & $56 / F$ & Polyps (three) & Polyclonal & Plasma cells and histiocytes & Positive \\
\hline 6 & Vaid et al. ${ }^{72}$ & NS & Submucosal tumor & Monoclonal (к) & Histiocytes & NS \\
\hline
\end{tabular}

F, female; NS, not stated; M, male; NA, not assessed. 

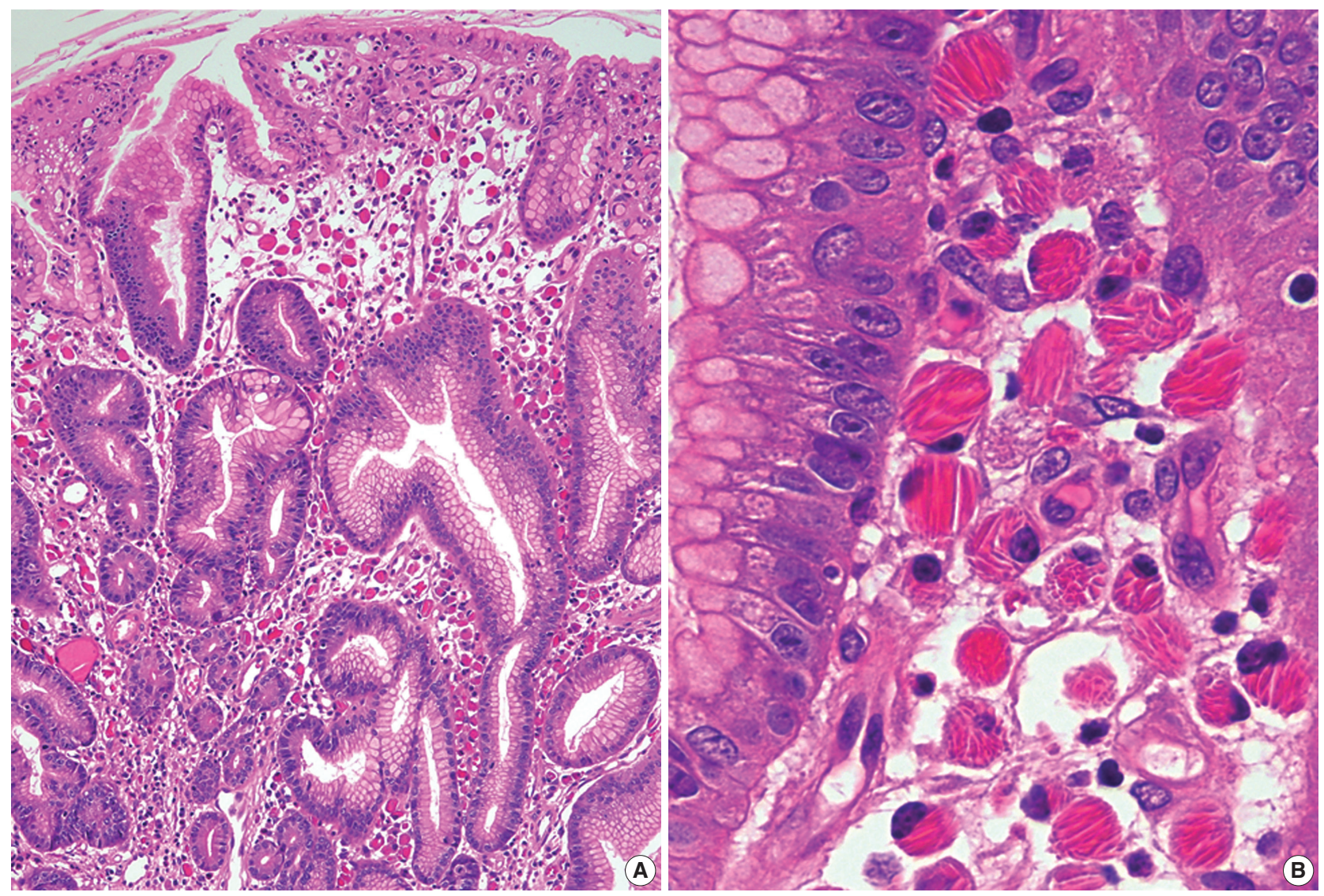

Fig. 4. Gastric crystal-storing histiocytosis. (A) The biopsy specimen demonstrates many large pinkish mononuclear cells in the lamina propria. (B) Higher magnification of mononuclear cells shows densely eosinophilic, refractile, needle-shaped, intracytoplasmic crystalline inclusions.

propriate patient management. In this context, $H$. pylori should be considered as a possible cause in areas where it is prevalent. Further investigation is needed to confirm the role of $H$. pylori in the development of rare gastric lesions.

\section{Conflicts of Interest}

No potential conflict of interest relevant to this article was reported.

\section{REFERENCES}

1. Dixon MF, Wyatt JI, Burke DA, Rathbone BJ. Lymphocytic gastritis-relationship to Campylobacter pylori infection. J Pathol 1988; 154: 125-32.

2. Carmack SW, Lash RH, Gulizia JM, Genta RM. Lymphocytic disorders of the gastrointestinal tract: a review for the practicing pathologist. Adv Anat Pathol 2009; 16: 290-306.

3. Genta RM, Lash RH. Helicobacter pylori-negative gastritis: seek, yet ye shall not always find. Am J Surg Pathol 2010; 34: e25-34.

4. Srivastava A, Lauwers GY. Pathology of non-infective gastritis. Histopathology 2007; 50: 15-29.

5. Wu TT, Hamilton SR. Lymphocytic gastritis: association with etiology and topology. Am J Surg Pathol 1999; 23: 153-8.

6. Ectors NL, Dixon MF, Geboes KJ, Rutgeerts PJ, Desmet VJ, Vantrappen GR. Granulomatous gastritis: a morphological and diagnostic approach. Histopathology 1993; 23: 55-61.

7. Maeng L, Lee A, Choi K, Kang CS, Kim KM. Granulomatous gastritis: a clinicopathologic analysis of 18 biopsy cases. Am J Surg Pathol 2004; 28: 941-5.

8. Paik S, Kim SH, Kim JH, Yang WI, Lee YC. Russell body gastritis associated with Helicobacter pylori infection: a case report. J Clin Pathol 2006; 59: 1316-9.

9. Zhang H, Jin Z, Cui R. Russell body gastritis/duodenitis: a case series and description of immunoglobulin light chain restriction. Clin Res Hepatol Gastroenterol 2014; 38: e89-97.

10. Stewart CJ, Spagnolo DV. Crystalline plasma cell inclusions in helicobacter-associated gastritis. J Clin Pathol 2006; 59: 851-4. 
11. Joo M, Kwak JE, Chang SH, et al. Localized gastric crystal-storing histiocytosis. Histopathology 2007; 51: 116-9.

12. Renault M, Goodier A, Subramony C, Hood B, Bishop P, Nowicki M. Age-related differences in granulomatous gastritis: a retrospective, clinicopathological analysis. J Clin Pathol 2010; 63: 347-50.

13. Hayat M, Arora DS, Dixon MF, Clark B, O'Mahony S. Effects of Helicobacter pylori eradication on the natural history of lymphocytic gastritis. Gut 1999; 45: 495-8.

14. Madisch A, Miehlke S, Neuber F, et al. Healing of lymphocytic gastritis after Helicobacter pylori eradication therapy--a randomized, double-blind, placebo-controlled multicentre trial. Aliment Pharmacol Ther 2006; 23: 473-9.

15. Müller H, Volkholz H, Stolte M. Healing of lymphocytic gastritis by eradication of Helicobacter pylori. Digestion 2001; 63: 14-9.

16. Niemelä S, Karttunen T, Kerola T, Karttunen R. Ten year follow up study of lymphocytic gastritis: further evidence on Helicobacter pylori as a cause of lymphocytic gastritis and corpus gastritis. J Clin Pathol 1995; 48: 1111-6.

17. Miyamoto M, Haruma K, Yoshihara M, et al. Isolated granulomatous gastritis successfully treated by Helicobacter pylori eradication: a possible association between granulomatous gastritis and Helicobacter pylori. J Gastroenterol 2003; 38: 371-5.

18. Ozturk Y, Buyukgebiz B, Ozer E, Arslan N, Bekem O, Hizli S. Resolution of Helicobacter pylori associated granulomatous gastritis in a child after eradication therapy. J Pediatr Gastroenterol Nutr 2004; 39: 286-7.

19. Tazawa K, Tsutsumi Y. Localized accumulation of Russell bodycontaining plasma cells in gastric mucosa with Helicobacter pylori infection: 'Russell body gastritis'. Pathol Int 1998; 48: 242-4.

20. Wolkersdörfer GW, Haase M, Morgner A, Baretton G, Miehlke S. Monoclonal gammopathy of undetermined significance and Russell body formation in Helicobacter pylori gastritis. Helicobacter 2006; 11: 506-10.

21. Yoon JB, Lee TY, Lee JS, et al. Two cases of Russell body gastritis treated by Helicobacter pylori eradication. Clin Endosc 2012; 45: 412-6.

22. Dhillon AP, Sawyerr A. Granulomatous gastritis associated with Campylobacter pylori. APMIS 1989; 97: 723-7.

23. Delgado JS, Landa E, Ben-Dor D. Granulomatous gastritis and Helicobacter pylori infection. Isr Med Assoc J 2013; 15: 317-8.

24. Koyama S, Nagashima F. Idiopathic granulomatous gastritis with multiple aphthoid ulcers. Intern Med 2003; 42: 691-5.

25. Haot J, Hamichi L, Wallez L, Mainguet P. Lymphocytic gastritis: a newly described entity: a retrospective endoscopic and histological study. Gut 1988; 29: 1258-64.

26. Haot J, Jouret A, Willette M, Gossuin A, Mainguet P. Lymphocytic gastritis: prospective study of its relationship with varioliform gastritis. Gut 1990; 31: 282-5.

27. Nielsen JA, Roberts CA, Lager DJ, Putcha RV, Jain R, Lewin M. Lymphocytic gastritis is not associated with active Helicobacter pylori infection. Helicobacter 2014; 19: 349-55.

28. Feeley KM, Heneghan MA, Stevens FM, McCarthy CF. Lymphocytic gastritis and coeliac disease: evidence of a positive association. J Clin Pathol 1998; 51: 207-10.

29. Alsaigh N, Odze R, Goldman H, Antonioli D, Ott MJ, Leichtner A. Gastric and esophageal intraepithelial lymphocytes in pediatric celiac disease. Am J Surg Pathol 1996; 20: 865-70.

30. Bhatti TR, Jatla M, Verma R, Bierly P, Russo PA, Ruchelli ED. Lymphocytic gastritis in pediatric celiac disease. Pediatr Dev Pathol 2011; 14: 280-3.

31. Oberhuber G, Vogelsang H, Stolte M, Muthenthaler S, Kummer JA, Radaszkiewicz T. Evidence that intestinal intraepithelial lymphocytes are activated cytotoxic $\mathrm{T}$ cells in celiac disease but not in giardiasis. Am J Pathol 1996; 148: 1351-7.

32. Inagaki-Ohara K, Nishimura H, Sakai T, Lynch DH, Yoshikai Y. Potential for involvement of Fas antigen/Fas ligand interaction in apoptosis of epithelial cells by intraepithelial lymphocytes in murine small intestine. Lab Invest 1997; 77: 421-9.

33. Han SH, Joo M, Kim KM. High proportion of granzyme B+ intraepithelial lymphocytes contributes to epithelial apoptosis in Helicobacter pylori-associated lymphocytic gastritis. Helicobacter 2013; 18: 290-8.

34. Oberhuber G, Bodingbauer M, Mosberger I, Stolte M, Vogelsang H. High proportion of granzyme B-positive (activated) intraepithelial and lamina propria lymphocytes in lymphocytic gastritis. Am J Surg Pathol 1998; 22: 450-8.

35. Shapiro JL, Goldblum JR, Petras RE. A clinicopathologic study of 42 patients with granulomatous gastritis. Is there really an "idiopathic" granulomatous gastritis? Am J Surg Pathol 1996; 20: 462-70.

36. El Demellawy D, Otero C, Radhi J. Primary gastric lymphoma with florid granulomatous reaction. J Gastrointestin Liver Dis 2009; 18: 99-101.

37. Fahimi HD, Deren JJ, Gottlieb LS, Zamcheck N. Isolated granulomatous gastritis: its relationship to disseminated sarcoidosis and regional enteritis. Gastroenterology 1963; 45: 161-75.

38. Sandmeier D, Bouzourene H. Does idiopathic granulomatous gastritis exist? Histopathology 2005; 46: 352-3.

39. Kim YS, Lee HK, Kim JO, et al. A case of H. pylori-associated granulomatous gastritis with hypertrophic gastropathy. Gut Liver 2009; 3 : 137-40.

40. Fuentebella J, Bass D, Longacre T, Ro K. Abdominal pain, gastrointestinal bleeding, and weight loss in a 17-year-old male. Dig Dis Sci 
2009; 54: 722-4.

41. Gonen C, Sarioglu S, Akpinar H. Magnifying endoscopic features of granulomatous gastritis. Dig Dis Sci 2009; 54: 1602-3.

42. Yamane T, Uchiyama K, Ishii T, et al. Isolated granulomatous gastritis showing discoloration of lesions after Helicobacter pylori eradication. Dig Endosc 2010; 22: 140-3.

43. Jones D, Bhatia VK, Krausz T, Pinkus GS. Crystal-storing histiocytosis: a disorder occurring in plasmacytic tumors expressing immunoglobulin kappa light chain. Hum Pathol 1999; 30: 1441-8.

44. Gebbers JO, Otto HF. Plasma cell alterations in ulcerative colitis: an electron microscopic study. Pathol Eur 1976; 11: 271-9.

45. van den Tweel JG, Taylor CR, Parker JW, Lukes RJ. Immunoglobulin inclusions in non-Hodgkin's lymphomas. Am J Clin Pathol 1978; 69: 306-13

46. Hasegawa H. Aggregates, crystals, gels, and amyloids: intracellular and extracellular phenotypes at the crossroads of immunoglobulin physicochemical property and cell physiology. Int J Cell Biol 2013; 2013: 604867.

47. Valetti C, Grossi CE, Milstein C, Sitia R. Russell bodies: a general response of secretory cells to synthesis of a mutant immunoglobulin which can neither exit from, nor be degraded in, the endoplasmic reticulum. J Cell Biol 1991; 115: 983-94.

48. Joo M. Gastric mucosa-associated lymphoid tissue lymphoma masquerading as Russell body gastritis. Pathol Int 2015; 65: 396-8.

49. Erbersdobler A, Petri S, Lock G. Russell body gastritis: an unusual, tumor-like lesion of the gastric mucosa. Arch Pathol Lab Med 2004; 128: 915-7.

50. Ensari A, Savas B, Okcu Heper A, Kuzu I, Idilman R. An unusual presentation of Helicobacter pylori infection: so-called "Russell body gastritis". Virchows Arch 2005; 446: 463-6.

51. Drut R, Olenchuk AB. Images in pathology: Russell body gastritis in an HIV-positive patient. Int J Surg Pathol 2006; 14: 141-2.

52. Pizzolitto S, Camilot D, DeMaglio G, Falconieri G. Russell body gastritis: expanding the spectrum of Helicobacter pylori-related diseases? Pathol Res Pract 2007; 203: 457-60.

53. Licci S, Sette P, Del Nonno F, Ciarletti S, Antinori A, Morelli L. Russell body gastritis associated with Helicobacter pylori infection in an HIV-positive patient: case report and review of the literature. Z Gastroenterol 2009; 47: 357-60.

54. Habib C, Gang DL, Ghaoui R, Pantanowitz L. Russell body gastritis. Am J Hematol 2010; 85: 951-2.

55. Shinozaki A, Ushiku T, Fukayama M. Prominent Mott cell proliferation in Epstein-Barr virus-associated gastric carcinoma. Hum Pathol 2010; $41: 134-8$

56. Del Gobbo A, Elli L, Braidotti P, Di Nuovo F, Bosari S, Romagnoli S. Helicobacter pylori-negative Russell body gastritis: case report. World
J Gastroenterol 2011; 17: 1234-6.

57. Wolf EM, Mrak K, Tschmelitsch J, Langner C. Signet ring cell cancer in a patient with Russell body gastritis: a possible diagnostic pitfall. Histopathology 2011; 58: 1178-80.

58. Coyne JD, Azadeh B. Russell body gastritis: a case report. Int J Surg Pathol 2012; 20: 69-70.

59. Bhalla A, Mosteanu D, Gorelick S, Hani el F. Russell body gastritis in an HIV positive patient: case report and review of literature. Conn Med 2012; 76: 261-5.

60. Karabagli P, Gokturk HS. Russell body gastritis: case report and review of the literature. J Gastrointestin Liver Dis 2012; 21: 97-100.

61. Araki D, Sudo Y, Imamura Y, Tsutsumi Y. Russell body gastritis showing IgM kappa-type monoclonality. Pathol Int 2013; 63: 565-7.

62. Soltermann A, Koetzer S, Eigenmann F, Komminoth P. Correlation of Helicobacter pylori virulence genotypes vacA and cagA with histological parameters of gastritis and patient's age. Mod Pathol 2007; 20: 878-83

63. Giron JA, Shah SL. Helicobacter pylori infection and light chain gammopathy. Clin Dev Immunol 2013; 2013: 348562.

64. Lebeau A, Zeindl-Eberhart E, Müller EC, et al. Generalized crystalstoring histiocytosis associated with monoclonal gammopathy: molecular analysis of a disorder with rapid clinical course and review of the literature. Blood 2002; 100: 1817-27.

65. Dogan S, Barnes L, Cruz-Vetrano WP. Crystal-storing histiocytosis: report of a case, review of the literature ( 80 cases) and a proposed classification. Head Neck Pathol 2012; 6: 111-20.

66. Ionescu DN, Pierson DM, Qing G, Li M, Colby TV, Leslie KO. Pulmonary crystal-storing histiocytoma. Arch Pathol Lab Med 2005; 129: 1159-63.

67. Hirota S, Miyamoto M, Kasugai T, Kitamura Y, Morimura Y. Crystalline light-chain deposition and amyloidosis in the thyroid gland and kidneys of a patient with myeloma. Arch Pathol Lab Med 1990; 114: 429-31.

68. Stirling JW, Henderson DW, Rozenbilds MA, Skinner JM, Filipic M. Crystalloidal paraprotein deposits in the cornea: an ultrastructural study of two new cases with tubular crystalloids that contain IgG kappa light chains and IgG gamma heavy chains. Ultrastruct Pathol 1997; 21: 337-44.

69. Papla B, Spólnik P, Rzenno E, et al. Generalized crystal-storing histiocytosis as a presentation of multiple myeloma: a case with a possible pro-aggregation defect in the immunoglobulin heavy chain. Virchows Arch 2004; 445: 83-9.

70. Llobet M, Castro P, Barceló C, Trull JM, Campo E, Bernadó L. Massive crystal-storing histicytosis associated with low-grade malignant B-cell lymphoma of MALT-type of the parotid gland. Diagn Cytopathol 1997; 17: 148-52. 
71. Kanagal-Shamanna R, Xu-Monette ZY, Miranda RN, et al. Crystalstoring histiocytosis: a clinicopathological study of 13 cases. Histopathology 2016; 68: 482-91.

72. Vaid A, Caradine KD, Lai KK, Rego R. Isolated gastric crystal-storing histiocytosis: a rare marker of occult lymphoproliferative disorders. J Clin Pathol 2014; 67: 740-1.

73. Kapadia SB, Enzinger FM, Heffner DK, Hyams VJ, Frizzera G. Crys- tal-storing histiocytosis associated with lymphoplasmacytic neoplasms: report of three cases mimicking adult rhabdomyoma. Am J Surg Pathol 1993; 17: 461-7.

74. Kusakabe T, Watanabe K, Mori T, lida T, Suzuki T. Crystal-storing histiocytosis associated with MALT lymphoma of the ocular adnexa: a case report with review of literature. Virchows Arch 2007; 450: 103-8. 